\title{
Mecanismos que controlam as características das águas dos reservatórios do estado de Sergipe, Nordeste do Brasil
}

Mechanisms that control the water characteristics of reservoirs in the state of Sergipe, Northeast Brazil

\author{
A. S. C. Monteiro ${ }^{1 *}$; E. L. Silva ${ }^{2}$; R. R. M. Silva ${ }^{1}$; J. P. H. Alves ${ }^{1}$ \\ ${ }^{1}$ Programa de Pós-Graduação em Recursos Hídricos, Universidade Federal de Sergipe, 49100-000, São Cristóvão- \\ Sergipe, Brasil \\ ${ }^{2}$ Instituto Federal de Ciência e Tecnologia do Piauí, Campus Floriano, 64800-000, Floriano - Piauí, Brasil.
}

*adniviacosta@hotmail.com

(Recebido em 31 de outubro de 2020; aceito em 12 de janeiro de 2021)

O diagrama de Gibbs foi usado para identificar os processos que potencialmente controlam as características químicas das águas dos principais reservatórios do estado de Sergipe, no Nordeste do Brasil. A água do reservatório Poxim controlada inicialmente pela precipitação atmosférica, evoluiu rapidamente

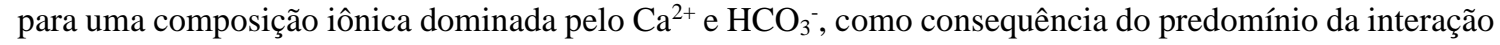
água - rocha. O intemperismo é o principal mecanismo que controla a química das águas dos reservatórios Jacarecica I, Jacarecica II, Macela, Ribeira e Jabiberi, com domínio iônico do $\mathrm{Na}^{+}$e $\mathrm{HCO}_{3}^{-}$, e dos reservatórios Dionísio, Ribeirópolis, Amargosa e Cumbe, com domínio iônico do $\mathrm{Na}^{+} \mathrm{e}^{-}$. A composição iônica atual da água dos reservatórios Taboca, Coité, Algodoeiro, Três Barras, Glória, Carira e Lagoa do Rancho é resultado das variações químicas provocadas pelos sucessivos processos de evaporação. Com o aumento da evaporação, a água foi salinizando e progressivamente mudando de $\mathrm{Na}^{+}>>\mathrm{Ca}^{2+}>\mathrm{Mg}^{2+} \mathrm{e} \mathrm{Cl}^{-}$ $>\mathrm{HCO}_{3}{ }^{-}>\mathrm{SO}_{4}{ }^{2-}$, em Taboca e Coité, para $\mathrm{Na}^{+}>>\mathrm{Mg}^{2+}>\mathrm{Ca}^{2+} \mathrm{e} \mathrm{Cl}^{-}>>\mathrm{HCO}_{3}{ }^{-}>\mathrm{SO}_{4}{ }^{2-}$ em Três Barras e Algodoeiro, atingindo finalmente $\mathrm{Na}^{+}>>>\mathrm{Mg}^{2+}>\mathrm{Ca}^{2+}$ e $\mathrm{Cl}^{-} \gg>\mathrm{SO}_{4}{ }^{2-}>\mathrm{HCO}_{3}{ }^{-}$em Glória, Carira e Lagoa do Rancho, reservatórios mais salinizados. Em geral, as características químicas das águas dos reservatórios foram controladas por processos naturais, como a interação água - rocha e a evaporação, exceto para os reservatórios Glória, Carira e Lagoa do Rancho, onde o impacto antropogênico mostrou uma contribuição muito expressiva.

Palavras-chave: composição iônica, intemperismo, evaporação

The Gibbs diagram was used to identify the processes that potentially control the water chemical characteristics of the main reservoirs in the state of Sergipe, in northeastern Brazil. The water in the Poxim reservoir, initially controlled by atmospheric precipitation, quickly evolved into an ionic composition dominated by $\mathrm{Ca}^{2+}$ and $\mathrm{HCO}_{3}{ }^{-}$, as a consequence of the predominance of water-rock interaction. Weathering is the main mechanism that controls the water chemistry of the Jacarecica I, Jacarecica II, Macela, Ribeira, and Jabiberi reservoirs, with $\mathrm{Na}^{+}$and $\mathrm{HCO}_{3}{ }^{-}$ionic domains, and the Dionísio, Ribeirópolis, Amargosa, and Cumbe reservoirs, with ionic domains. $\mathrm{Na}^{+}$and $\mathrm{Cl}^{-}$. The current ionic composition of water in the Taboca, Coité, Algodoeiro, Três Barras, Glória, Carira, and Lagoa do Rancho reservoirs is the result of chemical variations caused by successive evaporation processes. With the increase of evaporation, the water was salinizing and progressively changing from $\mathrm{Na}^{+}>>\mathrm{Ca}^{2+}>\mathrm{Mg}^{2+}$ and $\mathrm{Cl}^{-}>>\mathrm{HCO}_{3}{ }^{-}>\mathrm{SO}_{4}{ }^{2-}$ in Taboca and Coité, to $\mathrm{Na}^{+}>>\mathrm{Mg}^{2+}>\mathrm{Ca}^{2+}$ and $\mathrm{Cl}^{-}>>\mathrm{HCO}_{3}{ }^{-}>\mathrm{SO}_{4}{ }^{2-}$ in Três Barras and Algodoeiro, finally reaching $\mathrm{Na}^{+}$ >> $\mathrm{Mg}^{2+}>\mathrm{Ca}^{2+}$ and $\mathrm{Cl}^{-} \gg>\mathrm{SO}_{4}{ }^{2-}>\mathrm{HCO}_{3}{ }^{-}$in Glória, Carira, and Lagoa do Rancho, the most salinized reservoirs. In general, the chemical characteristics of the reservoir waters were controlled by natural processes, such as water-rock interaction and evaporation, except for the Glória, Carira and Lagoa do Rancho reservoirs, where the anthropogenic impact showed a very significant contribution.

Keywords: ionic composition, weathering, evaporation

\section{INTRODUÇÃO}

Cada corpo de água doce tem um padrão individual de características químicas que lhe é conferido pelo conteúdo mineral, ou seja, pelos íons dissolvidos na água. A composição iônica é controlada por uma variedade de processos geoquímicos que incluem o tipo de chuva, o grau de evaporação e o intemperismo das rochas e solos. Quando a água da chuva atravessa a atmosfera 
e drena a superfície do solo, dissolve espécies iônicas solúveis originárias dos gases e partículas de aerossóis da atmosfera e resultantes do intemperismo de rochas e solos, transportando esses constituintes para os rios e reservatórios [1,2].

A evaporação é um outro processo de controle dos constituintes dissolvidos na água, pois pela evaporação é removida água pura do ambiente aquático, levando ao aumento da concentração dos constituintes dissolvidos [1].

O intemperismo refere-se à interação entre a solução aquosa e a rocha, incluindo processos físicos e químicos. Essa interação leva a dissolução de minerais e a composição química da água reflete o equilíbrio entre as alterações induzidas pela dissolução dos minerais termodinamicamente instáveis e a formação de novos minerais estáveis. O grau de intemperismo depende principalmente do tempo de retenção da água, da temperatura ambiente e do $\mathrm{pH}$ [3-6].

O intemperismo é considerado a principal origem da composição iônica das águas superficiais e como os evaporitos, carbonatos e silicatos são os minerais mais solúveis e estão presentes nas rochas em maior quantidade, os íons mais importantes na composição química das águas são o $\mathrm{Na}^{+}, \mathrm{K}^{+}, \mathrm{Ca}^{2+} \mathrm{Mg}^{2+}, \mathrm{HCO}_{3}{ }^{-}, \mathrm{SO}_{4}{ }^{2-}$ e $\mathrm{Cl}^{-}[7,8,9]$.

A composição química da água também pode ser influenciada por atividades antropogênicas como agricultura, indústria e desenvolvimento urbano [10-14]. A irrigação é uma das atividades antropogênicas que mais tem contribuído para a aumento da composição mineral das águas, pois o retorno do fluxo da irrigação leva ao aumento do intemperismo do material existente no entorno da área irrigada. De acordo com Lerman (2009) [15] nos últimos séculos, os maiores impactos sobre lagos salinos, ocorreram durante a expansão agrícola e a extração de minerais.

$\mathrm{O}$ armazenamento de águas superficiais em reservatórios tem sido a estratégia mais utilizada, para atender a demanda em regiões caracterizadas pelo clima seco, com poucas chuvas e elevada evapotranspiração. Para muitos reservatórios situados em regiões áridas e semiáridas, onde a evaporação excede a precipitação, a salinização pode se tornar em um problema grave [16]. No Nordeste brasileiro, devido as condições climáticas adversas, a salinização das águas é um problema recorrente [17, 18], mas Santos et al. (2000) [19] advertem que a demanda irregular, resultante de um represamento sem planejamento adequado, também tem contribuído para a evolução da salinização.

Nos estudos hidroquímicos de águas superficiais, pouco é tratado sobre a composição iônica e os mecanismos que a controlam. Esse estudo se destaca por avaliar os mecanismos que contribuem para as características das águas dos principais reservatórios do Estado de Sergipe. Além disso, apresenta uma visão geral do estado hidroquímico de cada reservatório e discute os processos que potencialmente devem controlar as características químicas de suas águas e que levaram a composição iônica atual.

\section{MATERIAL E MÉTODOS}

\section{1 Área de Estudo}

Os reservatórios estão distribuídos no território sergipano nas regiões do Alto Sertão (Algodoeiro, Lagoa do Rancho, Glória); Médio Sertão (Cumbe, Três Barras); Agreste Central (Ribeirópolis, Macela, Jacarecica I, Jacarecica II, Ribeira, Carira, Coité); Centro Sul (Taboca, Dionísio, Amargosa, Jabiberi) e Grande Aracaju (Poxim).

A Tabela 1 tem um resumo de informações sobre os reservatórios, como a bacia hidrográfica e o município onde estão localizados, ano de conclusão da construção, capacidade de acumulação e referências de estudos específicos sobre cada um deles. 
Tabela 1: Localização e capacidade de acumulação dos principais reservatórios do estado de Sergipe.

\begin{tabular}{|c|c|c|c|c|}
\hline Bacia & Cidade & $\begin{array}{l}\text { Reservatório/ } \\
\text { ano conclusão }\end{array}$ & $\begin{array}{c}\text { Capacidade } \\
\left(\mathrm{m}^{3}\right)\end{array}$ & Referência \\
\hline \multirow{3}{*}{ Rio São Francisco } & N. Sra. da Glória & Algodoeiro/1966 & 1.868 .830 & \multirow{2}{*}{ [29] } \\
\hline & Graccho Cardoso & Três Barras/1965 & 7.980 .000 & \\
\hline & Porto da Folha & Lagoa do Rancho/1969 & 1.610 .000 & {$[30]$} \\
\hline Rio Japaratuba & Cumbe & Cumbe/1958 & 990.000 & [21] \\
\hline \multirow{6}{*}{ Rio Sergipe } & N. Sra. da Glória & Glória/1958 & 580.000 & {$[31]$} \\
\hline & Ribeirópolis & Ribeirópolis/1956 & 920.000 & {$[21]$} \\
\hline & Itabaiana & Macela/1957 & 2.710 .000 & {$[27]$} \\
\hline & Itabaiana & Jacarecica I/1987 & 4.700 .000 & {$[24]$} \\
\hline & Malhador & Jacarecica II & 30.400 .000 & [26] \\
\hline & São Cristóvão & Poxim/2013 & 32.730 .000 & {$[25]$} \\
\hline \multirow{3}{*}{ Rio Vaza-Barris } & Campo do Brito & Ribeira/1987 & 16.500 .000 & [32] \\
\hline & Carira & Carira/1955 & 822.000 & \multirow{2}{*}[20]{} \\
\hline & Frei Paulo & Coité/1932 & 820.000 & \\
\hline \multirow{2}{*}{ Rio Piauí } & Simão Dias & Taboca/1914 & 115.000 & \multirow{2}{*}[33]{} \\
\hline & Lagarto & Dionísio/1987 & 15.000 .000 & \\
\hline \multirow{2}{*}{ Rio Real } & Poço Verde & Amargosa1985 & 4.300 .000 & \multirow{2}{*}[33]{} \\
\hline & Tobias Barreto & Jabiberi/1987 & 4.300 .000 & \\
\hline
\end{tabular}

O Alto Sertão tem um clima subúmido seco, com baixo ou nenhum excesso de água durante o ano. A temperatura média varia entre 24 e $26^{\circ} \mathrm{C}$ e a precipitação pluviométrica média anual varia entre $500 \mathrm{~mm}$ e $800 \mathrm{~mm}$, sendo mal distribuída ao longo do ano e apresentando irregularidade de um ano para outro. No Médio Sertão sergipano, as precipitações médias anuais variam de $800 \mathrm{~mm}$ a $1600 \mathrm{~mm}$, com uma temperatura média anual de $23,9^{\circ} \mathrm{C}$ [20, 21]. A região Agreste Central corresponde a uma zona de transição entre o litoral e o sertão, e por isso tem um clima característico desses dois ambientes, variando de subsumido para semiárido brando. A temperatura média anual é de aproximadamente $26,2^{\circ} \mathrm{C}$ no período seco e $22,5^{\circ} \mathrm{C}$ no período chuvoso, com uma precipitação média anual de $886 \mathrm{~mm}$ [22, 23]. Na região Centro Sul o clima varia de tropical a semiárido quente, com precipitação anual média de $760 \mathrm{~mm}$ e as temperaturas médias mínimas mensais estão compreendidas entre 18 e $22^{\circ} \mathrm{C}$ e as temperaturas médias máximas mensais estão entre 26 e $32{ }^{\circ} \mathrm{C}$ [24]. As condições climáticas predominantes na região Grande Aracaju são o clima tropical úmido, com período seco de setembro a março e período chuvoso de abril a agosto, com precipitação anual variando de 1.600 a $1.900 \mathrm{~mm}$. A temperatura média é de $23{ }^{\circ} \mathrm{C}$, para os meses mais frios, junho a agosto, e de $31^{\circ} \mathrm{C}$ para os meses mais quentes, dezembro a fevereiro [25].

Os reservatórios em geral, foram projetados para atender principalmente a agricultura e o abastecimento humano. Hoje, em face da salinização de suas águas, os reservatórios Ribeirópolis, Glória, Carira, Coité, Algodoeiro, Três Barras e Lagoa do Rancho são utilizados apenas para a pesca, lazer e dessedentação animal.

Dentre os reservatórios usados para irrigação se destacam o reservatório Ribeira que fornece água para o perímetro irrigado Poção da Ribeira. A área total do empreendimento é de 1.970 ha, sendo 1100 ha a área irrigada. Os reservatórios Jacarecica I e Jacarecica II atendem respectivamente os perímetros irrigados do Jacarecica I e Jacarecica II, com um total de área irrigada de 1070 ha. O reservatório Dionísio Machado atende ao perímetro irrigado Piauí, com uma área irrigada de 703 ha, e o reservatório Jabiberi ao perímetro irrigado Jabiberi com uma área 
irrigada de 225 ha [26]. As águas do reservatório Macela também são usadas para irrigação de uma área de 156 hectares [27].

Em relação a litologia, predominam nas áreas dos reservatórios as fácies ígneas e metamórficas, com uma composição gnáissico e migmatítico e solos do tipo planossolos. Os principais minerais associados a essas rochas são o quartzo, feldspato, mica, biotita e plagioclásio. Os minerais halita, dolomita e gipsita também são encontrados na área, nas margas de arenito, calcário e gipsita [28].

\subsection{Amostragem e análises}

Neste estudo foram utilizados os dados obtidos no Programa de Monitoramento da Qualidade da Água (PMQA) das Bacias Hidrográficas do Estado de Sergipe [34], para as seguintes variáveis: temperatura, $\mathrm{pH}$, condutividade elétrica (CE), sólidos totais dissolvidos (STD), sódio $\left(\mathrm{Na}^{+}\right)$, potássio $\left(\mathrm{K}^{+}\right)$, cálcio $\left(\mathrm{Ca}^{2+}\right)$, magnésio $\left(\mathrm{Mg}^{2+}\right)$, cloreto $\left(\mathrm{Cl}^{-}\right)$, sulfato $\left(\mathrm{SO}_{4}^{2-}\right)$ e bicarbonatos $\left(\mathrm{HCO}_{3}{ }^{-}\right)$. Foram coletadas amostras de água de superfície em uma estação de amostragem em cada um dos reservatórios (Figura 1), nos períodos seco e chuvoso, no intervalo temporal de 2013 a 2018. O pH e a temperatura foram medidas no campo (in situ), a condutividade elétrica foi medida no laboratório com condutivímetro e os sólidos totais dissolvidos calculados pela medida da condutividade elétrica e os demais parâmetros foram determinados no Laboratório de Água do Instituto Tecnológico e de Pesquisas do Estado de Sergipe (ITPS), usando a metodologia descrita no APHA (2012) [35]. Para determinação da composição iônica as amostras foram filtradas a vácuo através de membranas de $0,45 \mu \mathrm{m}$ e as determinações das concentrações iônicas foram realizadas por meio de cromatografia iônica usando um cromatógrafo iônico modelo Dionex ICS 3000 com detecção por condutividade.

A precisão das análises foi determinada por meio do balanço iônico, usando a equação 1 :

$$
A=\left(\frac{\sum \text { cátions }-\sum \text { ânions }}{\sum \text { cátions }+\sum \text { ânions }}\right) \times 100
$$

Onde,

$\sum$ cátions $=$ somatório das concentrações em meq $\mathrm{L}^{-1} \mathrm{de}^{2+} \mathrm{Ca}^{2+} \mathrm{Mg}^{2+}, \mathrm{Na}^{+}$e $\mathrm{K}^{+}$;

$\sum$ ânions = somatório das concentrações em meq $\mathrm{L}^{-1} \mathrm{de} \mathrm{HCO}_{3}^{-}, \mathrm{SO}_{4}^{-2}, \mathrm{Cl}^{-} \mathrm{e}$

A é a percentagem de erro do balanço iônico.

O valor de A, para as amostras dos reservatórios variaram de $-7,8 \%$ a $6,1 \%$ com um valor médio absoluto de 2,2 $\pm 1,7 \%$. De acordo com Yaouti et al. (2009) [36] um erro de $\pm 10 \%$ no balanço iônico é aceitável para esse tipo de estudo. 


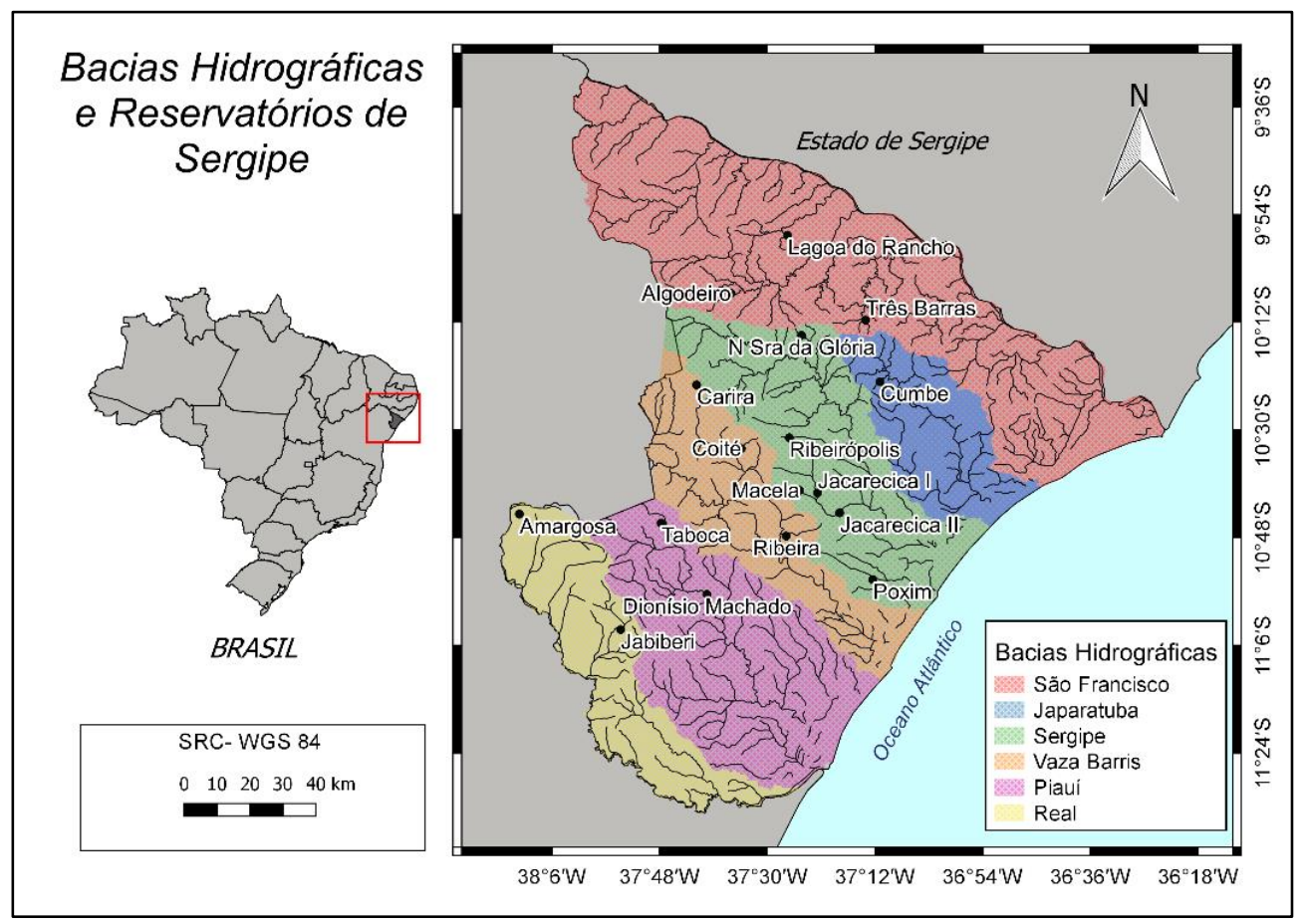

Figura 1: Área de estudo com a indicação dos reservatórios e dos respectivos pontos de amostragem.

\subsection{Análise estatística multivariada}

A análise de componentes principais (ACP) foi usada para entender melhor a variabilidade do conjunto dos dados das amostras dos reservatórios. A ACP resume o conjunto de dados em um mínimo de componentes que tanto quanto possível mantêm a confiabilidade dos dados originais. A redução é obtida transformando o conjunto de dados em novas variáveis, chamadas de componentes principais, as quais são ortogonais (não correlacionadas) e organizadas em ordem decrescente de importância [37, 38,39]

Os dados foram normalizados utilizando a técnica de z-score. Nessa técnica os dados normalizados possuem média igual a 0 e variância igual a 1 . A normalização é sempre recomendada no caso de dados de qualidade da água, que apresentam parâmetros com variâncias muito diferentes, com isso são reduzidas as influências dos parâmetros com elevada variabilidade [40].

Todos os testes foram realizados utilizando o programa PAST - Paleontological Statistics, versão 3.04 [41]. Um valor de 0,05 foi adotado como nível crítico para todos os testes estatísticos, dando um nível de confiança de $95 \%$.

\section{RESULTADOS E DISCUSSÃO}

\section{Hidroquímica dos reservatórios}

A estatística descritiva dos parâmetros medidos é apresentada na Tabela 2. Os valores do pH das águas dos reservatórios variaram de 7,3 a 8,3 com valor médio de 8,0 $\pm 0,3$ indicando que as amostras de água foram ligeiramente alcalinas. Os valores médios da CE variram de 156 a 21189 $\mu \mathrm{S} \mathrm{cm}{ }^{-1}$ o que mostra a grande variedade da qualidade da água dos reservatórios em relação a salinidade. O diagrama de Richards [42] permite classificar as águas para fins agrícolas com base nos valores da CE e por isso, foi usado para agrupar as águas dos reservatórios em relação ao nivel de salinização. As águas dos reservatórios se distribuiram em relação ao risco de salinização para uso em irrigação, em: baixo (Poxim); médio (Jacarecica I, Jacarecica II, Ribeira, Jabiberi); 
alto (Ribeirópolis, Macela, Cumbe, Dionísio, Amargosa); muito alto (Coité, Taboca) e excepcionalmente alto (Algodoeiro, Glória, Três Barras, Carira, Lagoa do Rancho).

Com base nos valores médios (Tabela 2) observou-se uma variação na ordem de abundância para cátions e ânions, em função do risco de salinização apresentado pelas águas dos reservatórios. Os reservatórios com risco baixo e médio mostraram a mesma abundancia ânionica $\left(\mathrm{HCO}_{3}{ }^{-}>\mathrm{Cl}^{-}>\mathrm{SO}_{4}{ }^{2-}\right)$, enquanto a abundância catiônica foi $\mathrm{Ca}^{2+}>\mathrm{Na}^{+}>\mathrm{Mg}^{2+}>\mathrm{K}^{+} \mathrm{e} \mathrm{Na}{ }^{+}>\mathrm{Ca}^{2+}$ $>\mathrm{Mg}^{2+}>\mathrm{K}^{+}$, respectivamente. Para os reservatórios com risco alto e muito alto, a abundância aniônica foi $\mathrm{Cl}^{-}>\mathrm{HCO}_{3}^{-}>\mathrm{SO}_{4}{ }^{2-}$, exceto para Macela $\left(\mathrm{HCO}_{3}^{-}>\mathrm{Cl}^{-}>\mathrm{SO}_{4}{ }^{2-}\right)$ e Dionísio $\left(\mathrm{Cl}^{-}>\right.$ $\left.\mathrm{SO}_{4}{ }^{2-}>\mathrm{HCO}_{3}{ }^{-}\right)$, e a abundancia catiônica foi $\mathrm{Na}^{+}>\mathrm{Ca}^{2+}>\mathrm{Mg}^{2+}>\mathrm{K}^{+}$, exceto para Cumbe $\left(\mathrm{Na}^{+}>\right.$ $\left.\mathrm{Mg}^{2+}>\mathrm{K}^{+}>\mathrm{Ca}^{2+}\right)$ e Amargosa $\left(\mathrm{Na}^{+}>\mathrm{Ca}^{2+}>\mathrm{K}^{+}>\mathrm{Mg}^{2+}\right)$. Os reservatórios com risco excepcionalmente alto mostraram três ordens diferentes de abundância iônica, assim distribuidas: (a) Algodoeiro e Três Barras $\left(\mathrm{Na}^{+}>\mathrm{Mg}^{2+}>\mathrm{Ca}^{2+}>\mathrm{K}^{+}, \mathrm{Cl}^{-}>\mathrm{HCO}_{3}^{-}>\mathrm{SO}_{4}{ }^{2-}\right)$; (b) Carira e Glória $\left(\mathrm{Na}^{+}>\mathrm{Mg}^{2+}>\mathrm{Ca}^{2+}>\mathrm{K}^{+}, \mathrm{Cl}^{-}>\mathrm{SO}_{4}{ }^{2-}>\mathrm{HCO}_{3}\right)$ e (c) Lagoa do Rancho $\left(\mathrm{Na}^{+}>\mathrm{Ca}^{2+}>\mathrm{Mg}^{2+}>\mathrm{K}^{+}\right.$, $\mathrm{Cl}^{-}>\mathrm{SO}_{4}{ }^{2-}>\mathrm{HCO}_{3}{ }^{-}$). De um modo geral se observou que a medida que vai aumentando os valores dos STD na água, ou seja aumentando a salinização, o $\mathrm{Ca}^{2+}$ vai sendo substituido pelo $\mathrm{Na}^{+}$e o $\mathrm{HCO}_{3}{ }^{-}$pelo $\mathrm{Cl}^{-}$. Verifica-se que quando a água atinge niveis muito elevados de salinização a concentração do $\mathrm{Mg}^{2+}$ passa a ser maior que a do $\mathrm{Ca}^{2+}$.

A técnica estatística multivariada de análise de componentes principais (ACP) foi aplicada ao conjunto dos dados, para melhor compreender as diferenças entre as características químicas das águas dos reservatórios e identificar os possíveis fatores que contribuíram para essas diferenças. A matriz dos dados foi constituída por 17 objetos e 11 variáveis. Os objetos foram os 17 reservatórios estudados e as variáveis foram compostas pela média de cada um dos reservatórios, referentes aos parâmetros ( $\mathrm{pH}, \mathrm{CE}, \mathrm{STD}$, Temperatura, $\mathrm{Na}^{+}, \mathrm{K}^{+}, \mathrm{Ca}^{2+}, \mathrm{Mg}^{2+}, \mathrm{SO}_{4}{ }^{2-}, \mathrm{Cl}^{-}, \mathrm{HCO}_{3}{ }^{-}$) medidos nas 8 amostras coletadas em cada um deles, no período 2013 a 2018.

A ACP mostrou que as três primeiras componentes representam juntas 92,3 \% (CP1 70,5 \%; CP2 13,4 \%; CP3 8,4 \%) das informações contidas nas variáveis iniciais. Baseados no peso de contribuição de cada variável (Tabela 3) pode se observar que a CP1 está fortemente associadas (peso > 0,700) com a CE, STD e os íons $\mathrm{Na}^{+}, \mathrm{K}^{+}, \mathrm{Ca}^{2+}, \mathrm{Mg}^{2+}, \mathrm{SO}_{4}{ }^{2-} \mathrm{e} \mathrm{Cl}^{-}$, enquanto a $\mathrm{CP} 2$ tem uma associação forte negativa com o $\mathrm{HCO}_{3}{ }^{-}$e a $\mathrm{CP} 3$ tem forte correlação com os STD. 
Tabela 2: Estatística descritiva dos parâmetros medidos para a água dos reservatórios. Média das amostras coletadas no periodo 2013 a 2018 e entre parênteses os valores mínimo e máximo. ( $T=$ temperatura,$C E=$ condutividade elétrica, $S T D=$ sólidos totais dissolvidos $)$.

\begin{tabular}{|c|c|c|c|c|c|c|c|c|c|c|c|}
\hline Reservatório & $\mathrm{pH}$ & $\begin{array}{l}\mathrm{T} \\
{ }^{\circ} \mathrm{C}\end{array}$ & $\begin{array}{c}\mathrm{CE} \\
\mu \mathrm{S} \mathrm{cm}^{-1}\end{array}$ & $\begin{array}{l}\text { STD } \\
\mathrm{mg} \mathrm{L}^{-1}\end{array}$ & $\begin{array}{c}\mathrm{Na}^{+} \\
\mathrm{mg} \mathrm{L}^{-1}\end{array}$ & $\begin{array}{c}\mathrm{K}^{+} \\
\mathrm{mg} \mathrm{L}^{-1}\end{array}$ & $\begin{array}{c}\mathrm{Ca}^{2+} \\
\mathrm{mg} \mathrm{L}^{-1}\end{array}$ & $\begin{array}{l}\mathrm{Mg}^{2+} \\
\mathrm{mg} \mathrm{L}^{-1}\end{array}$ & $\begin{array}{l}\mathrm{SO}_{4}{ }^{2-} \\
\mathrm{mg} \mathrm{L}^{-1}\end{array}$ & $\begin{array}{c}\mathrm{Cl}^{-} \\
\mathrm{mg} \mathrm{L}^{-1}\end{array}$ & $\begin{array}{l}\mathrm{HCO}_{3}^{-} \\
\mathrm{mg} \mathrm{L}^{-1}\end{array}$ \\
\hline Algodoeiro & $\begin{array}{c}8,3 \\
(7,7-8,6)\end{array}$ & $\begin{array}{c}26,6 \\
(24,1-30,4)\end{array}$ & $\begin{array}{c}5915 \\
(4107-9124)\end{array}$ & $\begin{array}{c}3637 \\
(2658-5109)\end{array}$ & $\begin{array}{c}744 \\
(449-1143)\end{array}$ & $\begin{array}{c}22,7 \\
(15,1-36,1)\end{array}$ & $\begin{array}{c}119 \\
(77,3-229)\end{array}$ & $\begin{array}{c}180 \\
(141-219)\end{array}$ & $\begin{array}{c}162 \\
(23,0-480)\end{array}$ & $\begin{array}{c}1707 \\
(1037-2375)\end{array}$ & $\begin{array}{c}178 \\
(122-204)\end{array}$ \\
\hline $\begin{array}{l}\text { Lagoa do } \\
\text { Rancho }\end{array}$ & $\begin{array}{c}8,2 \\
(6,9-9,1)\end{array}$ & $\begin{array}{c}27,4 \\
(25,5-29,8)\end{array}$ & $\begin{array}{c}21189 \\
(2256-70930)\end{array}$ & $\begin{array}{c}15199 \\
(1343-48940)\end{array}$ & $\begin{array}{c}3707 \\
(180-13510)\end{array}$ & $\begin{array}{c}72,0 \\
(13,6-245)\end{array}$ & $\begin{array}{c}516 \\
(91,7-1544)\end{array}$ & $\begin{array}{c}557 \\
(97,7-1099)\end{array}$ & $\begin{array}{c}1027 \\
(120-3657)\end{array}$ & $\begin{array}{c}7656 \\
(571-25318)\end{array}$ & $\begin{array}{c}116 \\
(48,3-218)\end{array}$ \\
\hline Três Barras & $\begin{array}{c}8,3 \\
(7,5-8,6)\end{array}$ & $\begin{array}{c}26,6 \\
(24,7-29,0) \\
\end{array}$ & $\begin{array}{c}11575 \\
(6056-15821)\end{array}$ & $\begin{array}{c}7250 \\
(3952-8860)\end{array}$ & $\begin{array}{c}1547 \\
(794-2238)\end{array}$ & $\begin{array}{c}34,6 \\
(15,4-54,3)\end{array}$ & $\begin{array}{c}241 \\
(77,6-377)\end{array}$ & $\begin{array}{c}341 \\
(148-501)\end{array}$ & $\begin{array}{c}64,3 \\
(34,2-98,4)\end{array}$ & $\begin{array}{c}3748 \\
(1645-4656)\end{array}$ & $\begin{array}{c}177 \\
(139-217)\end{array}$ \\
\hline $\begin{array}{l}\text { N. Sra. da } \\
\text { Glória }\end{array}$ & $\begin{array}{c}8,6 \\
(8,2-9,0)\end{array}$ & $\begin{array}{c}24,4 \\
(23,4-28,9) \\
\end{array}$ & $\begin{array}{c}10696 \\
(7750-12104)\end{array}$ & $\begin{array}{c}6791 \\
(4340-8110) \\
\end{array}$ & $\begin{array}{c}1338 \\
(1025-1626)\end{array}$ & $\begin{array}{c}126 \\
(47,4-252)\end{array}$ & $\begin{array}{c}248 \\
(64,6-793) \\
\end{array}$ & $\begin{array}{c}406 \\
(262-256)\end{array}$ & $\begin{array}{c}485 \\
62,9-2113\end{array}$ & $\begin{array}{c}3261 \\
2493-3721 \\
\end{array}$ & $\begin{array}{c}355 \\
168-622\end{array}$ \\
\hline Ribeirópolis & $\begin{array}{c}8,2 \\
(7,9-8,8)\end{array}$ & $\begin{array}{c}26,6 \\
(23,8-30,4)\end{array}$ & $\begin{array}{c}1595 \\
(1411-1866)\end{array}$ & $\begin{array}{c}1059 \\
(973-1150)\end{array}$ & $\begin{array}{c}155 \\
(119-182)\end{array}$ & $\begin{array}{c}15,2 \\
(11,0-18,5)\end{array}$ & $\begin{array}{c}54,9 \\
(35,8-67,9)\end{array}$ & $\begin{array}{c}54,6 \\
(34,7-79,0)\end{array}$ & $\begin{array}{c}14,3 \\
(6,4-20,1)\end{array}$ & $\begin{array}{c}329 \\
(275-404)\end{array}$ & $\begin{array}{c}200 \\
(183-224)\end{array}$ \\
\hline Macela & $\begin{array}{c}7,7 \\
(7,3-8,4) \\
\end{array}$ & $\begin{array}{c}26,0 \\
(21,1-28,0) \\
\end{array}$ & $\begin{array}{c}1177 \\
(972-2000) \\
\end{array}$ & $\begin{array}{c}753 \\
(594-1380) \\
\end{array}$ & $\begin{array}{c}117 \\
(82,6-138) \\
\end{array}$ & $\begin{array}{c}17,6 \\
(11,7-31,6) \\
\end{array}$ & $\begin{array}{c}33,2 \\
(26,0-39,9) \\
\end{array}$ & $\begin{array}{c}26,8 \\
(17,7-34,3) \\
\end{array}$ & $\begin{array}{c}34,7 \\
(24,0-43,1) \\
\end{array}$ & $\begin{array}{c}155 \\
(114-179) \\
\end{array}$ & $\begin{array}{c}230 \\
(192-290) \\
\end{array}$ \\
\hline Jacarecica I & $\begin{array}{c}8,0 \\
(7,1-9,1)\end{array}$ & $\begin{array}{c}26,7 \\
(25,0-29,0) \\
\end{array}$ & $\begin{array}{c}400 \\
(220-537) \\
\end{array}$ & $\begin{array}{c}245 \\
(123-332)\end{array}$ & $\begin{array}{c}44,2 \\
(28,7-63,5) \\
\end{array}$ & $\begin{array}{c}5,5 \\
(1,3-8,5)\end{array}$ & $\begin{array}{c}24,6 \\
(9,2-45,8) \\
\end{array}$ & $\begin{array}{c}7,3 \\
(3,8-11,7)\end{array}$ & $\begin{array}{c}9,7 \\
(1,6-19,1) \\
\end{array}$ & $\begin{array}{c}68,2 \\
(38,5-91,2) \\
\end{array}$ & $\begin{array}{c}93,6 \\
(58,0-121)\end{array}$ \\
\hline Jacarecica II & $\begin{array}{c}7,3 \\
(6,9-7,6) \\
\end{array}$ & $\begin{array}{c}27,0 \\
(24,0-29,5) \\
\end{array}$ & $\begin{array}{c}355 \\
(269-465) \\
\end{array}$ & $\begin{array}{c}206 \\
(170-260) \\
\end{array}$ & $\begin{array}{c}39,1 \\
(25,7-44,3) \\
\end{array}$ & $\begin{array}{c}4,7 \\
(3,4-6,1) \\
\end{array}$ & $\begin{array}{c}14,8 \\
(8,6-22,7) \\
\end{array}$ & $\begin{array}{c}8,7 \\
(7,0-10,9) \\
\end{array}$ & $\begin{array}{c}7,1 \\
(4,6-9,9) \\
\end{array}$ & $\begin{array}{c}51,6 \\
(42,9-58,6) \\
\end{array}$ & $\begin{array}{c}84,5 \\
(71,0-98,3) \\
\end{array}$ \\
\hline Poxim & $\begin{array}{c}7,5 \\
(6,9-7,8) \\
\end{array}$ & $\begin{array}{c}27,7 \\
(25,0-30,0) \\
\end{array}$ & $\begin{array}{c}156 \\
(132-183) \\
\end{array}$ & $\begin{array}{c}90,2 \\
(81,0-111) \\
\end{array}$ & $\begin{array}{c}10,4 \\
(6,5-14,3) \\
\end{array}$ & $\begin{array}{c}1,62 \\
(0,8-3,6) \\
\end{array}$ & $\begin{array}{c}14,1 \\
(10,8-20,6) \\
\end{array}$ & $\begin{array}{c}2,5 \\
(1,9-3,5) \\
\end{array}$ & $\begin{array}{c}2,2 \\
(1,5-3,6) \\
\end{array}$ & $\begin{array}{c}16,5 \\
(13,2-19,9) \\
\end{array}$ & $\begin{array}{c}46,7 \\
(43,2-55,8) \\
\end{array}$ \\
\hline Cumbe & $\begin{array}{c}8,0 \\
(7,5-8,4)\end{array}$ & $\begin{array}{c}26,8 \\
(25,5-29,0) \\
\end{array}$ & $\begin{array}{c}1641 \\
(1351-1893) \\
\end{array}$ & $\begin{array}{c}1080 \\
(932-1186)\end{array}$ & $\begin{array}{c}237 \\
(199-265)\end{array}$ & $\begin{array}{c}13,2 \\
(9,4-18,2)\end{array}$ & $\begin{array}{c}12,8 \\
(7,6-19,7) \\
\end{array}$ & $\begin{array}{c}34,0 \\
(19,7-49,7) \\
\end{array}$ & $\begin{array}{c}14,3 \\
(5,7-19,7) \\
\end{array}$ & $\begin{array}{c}388 \\
(295-466) \\
\end{array}$ & $\begin{array}{c}168 \\
(122-242)\end{array}$ \\
\hline Ribeira & $\begin{array}{c}8,1 \\
(7,1-8,6)\end{array}$ & $\begin{array}{c}26,8 \\
(22,0-29,0) \\
\end{array}$ & $\begin{array}{c}518 \\
(365-870) \\
\end{array}$ & $\begin{array}{c}320 \\
(235-487) \\
\end{array}$ & $\begin{array}{c}45,6 \\
(31,8-60,4) \\
\end{array}$ & $\begin{array}{c}5,9 \\
(4,7-7,4)\end{array}$ & $\begin{array}{c}20,2 \\
(12,731,8)\end{array}$ & $\begin{array}{c}14,3 \\
(10,7-19,1) \\
\end{array}$ & $\begin{array}{c}11,5 \\
(5,8-17,6)\end{array}$ & $\begin{array}{c}79,8 \\
(70,7-90,0) \\
\end{array}$ & $\begin{array}{c}97,6 \\
(84,6-137) \\
\end{array}$ \\
\hline Carira & $\begin{array}{c}8,1 \\
(7,8-8,4)\end{array}$ & $\begin{array}{c}25,4 \\
(22,8-27,1) \\
\end{array}$ & $\begin{array}{c}11335 \\
(10007-12963)\end{array}$ & $\begin{array}{c}7085 \\
(5638-8505) \\
\end{array}$ & $\begin{array}{c}1529 \\
(1115-2391) \\
\end{array}$ & $\begin{array}{c}18,4 \\
(4,1-26,5)\end{array}$ & $\begin{array}{c}319 \\
(247-371)\end{array}$ & $\begin{array}{c}424 \\
(174-935)\end{array}$ & $\begin{array}{c}272 \\
(78,8-793)\end{array}$ & $\begin{array}{c}3697 \\
(3217-4766) \\
\end{array}$ & $\begin{array}{c}224 \\
(182-367) \\
\end{array}$ \\
\hline Coité & $\begin{array}{c}8,1 \\
7,5-8,4\end{array}$ & $\begin{array}{c}27,1 \\
25,2-30,0\end{array}$ & $\begin{array}{c}3719 \\
2264-7630\end{array}$ & $\begin{array}{c}2394 \\
1405-5365\end{array}$ & $\begin{array}{c}460 \\
322-881\end{array}$ & $\begin{array}{c}14,2 \\
9,3-22,0\end{array}$ & $\begin{array}{c}128 \\
74,4-211\end{array}$ & $\begin{array}{c}116 \\
93,0-173\end{array}$ & $\begin{array}{c}94,3 \\
60,5-191\end{array}$ & $\begin{array}{c}1087 \\
639-2087\end{array}$ & $\begin{array}{c}210 \\
128-266\end{array}$ \\
\hline Taboca & $\begin{array}{c}7,9 \\
7,5-8,1\end{array}$ & $\begin{array}{c}26,3 \\
23,0-30,0\end{array}$ & $\begin{array}{c}2408 \\
1313-4007\end{array}$ & $\begin{array}{c}1515 \\
906-2494\end{array}$ & $\begin{array}{c}238 \\
104-491\end{array}$ & $\begin{array}{c}8,5 \\
6,1-14,1\end{array}$ & $\begin{array}{c}142 \\
79,0-205\end{array}$ & $\begin{array}{c}93,5 \\
20,4-289\end{array}$ & $\begin{array}{c}140 \\
26,4-360\end{array}$ & $\begin{array}{c}675 \\
279-1313\end{array}$ & $\begin{array}{c}192 \\
125-262\end{array}$ \\
\hline $\begin{array}{c}\text { Dionísio } \\
\text { Machado }\end{array}$ & $\begin{array}{c}8,3 \\
7,1-9,5\end{array}$ & $\begin{array}{c}27,5 \\
25,0-30,6\end{array}$ & $\begin{array}{c}1235 \\
436-2162\end{array}$ & $\begin{array}{c}765 \\
301-1310\end{array}$ & $\begin{array}{c}156 \\
40,6-338\end{array}$ & $\begin{array}{c}4,4 \\
2,7-6,6\end{array}$ & $\begin{array}{c}49,5 \\
17,2-78,6\end{array}$ & $\begin{array}{c}41,3 \\
6,4-140\end{array}$ & $\begin{array}{c}91,2 \\
4,7-312\end{array}$ & $\begin{array}{c}319 \\
85,0-587\end{array}$ & $\begin{array}{c}90,9 \\
45,5-125\end{array}$ \\
\hline Amargosa & $\begin{array}{c}7,7 \\
7,4-8,0 \\
\end{array}$ & $\begin{array}{c}25,4 \\
22,8-29,5\end{array}$ & $\begin{array}{c}1521 \\
118-4175\end{array}$ & $\begin{array}{c}1043 \\
65,9-2881\end{array}$ & $\begin{array}{c}199 \\
6,0-579\end{array}$ & $\begin{array}{c}33,9 \\
7,6-83,1\end{array}$ & $\begin{array}{c}44,6 \\
12,3-105\end{array}$ & $\begin{array}{c}19,6 \\
4,0-34,4\end{array}$ & $\begin{array}{c}24,9 \\
2,4-66,8\end{array}$ & $\begin{array}{c}413 \\
6,8-1213\end{array}$ & $\begin{array}{c}83,5 \\
59,3-122 \\
\end{array}$ \\
\hline Jabiberi & $\begin{array}{c}7,4 \\
7,0-7,7 \\
\end{array}$ & $\begin{array}{c}26,0 \\
24,0-27,7 \\
\end{array}$ & $\begin{array}{c}294 \\
160-447 \\
\end{array}$ & $\begin{array}{c}180 \\
110-279 \\
\end{array}$ & $\begin{array}{c}38,4 \\
23,1-61,3 \\
\end{array}$ & $\begin{array}{c}6,3 \\
2,2-29,1 \\
\end{array}$ & $\begin{array}{c}11,4 \\
4,8-18,4 \\
\end{array}$ & $\begin{array}{c}5,6 \\
2,9-10,5 \\
\end{array}$ & $\begin{array}{c}17,9 \\
1,9-62,0\end{array}$ & $\begin{array}{c}58,0 \\
33,1-98,3 \\
\end{array}$ & $\begin{array}{c}46,9 \\
27,7-73,5 \\
\end{array}$ \\
\hline
\end{tabular}


Tabela 3: Pesos dos parâmetros experimentais para as duas primeiras componentes principais.

\begin{tabular}{lllc}
\hline Parâmetro & $\mathrm{CP} 1$ & $\mathrm{CP} 2$ & $\mathrm{CP3}$ \\
\hline $\mathrm{pH}$ & 0,642 & $-0,392$ & 0,504 \\
$\mathrm{~T}\left({ }^{\circ} \mathrm{C}\right)$ & $-0,007$ & 0,646 & $-0,083$ \\
$\mathrm{CE}\left(\mu \mathrm{S} \mathrm{cm}^{-1}\right)$ & $\mathbf{0 , 9 8 5}$ & 0,107 & $-0,082$ \\
$\mathrm{STD}\left(\mathrm{mg} \mathrm{L}^{-1}\right)$ & $\mathbf{0 , 9 8 1}$ & 0,159 & $\mathbf{0 , 7 4 5}$ \\
$\mathrm{Na}^{+}\left(\mathrm{mg} \mathrm{L}^{-1}\right)$ & $\mathbf{0 , 9 6 4}$ & 0,234 & $-0,095$ \\
$\mathrm{~K}^{+}\left(\mathrm{mg} \mathrm{L}^{-1}\right)$ & $\mathbf{0 , 7 6 9}$ & $-0,317$ & 0,131 \\
$\mathrm{Ca}^{2+}\left(\mathrm{mg} \mathrm{L}^{-1}\right)$ & $\mathbf{0 , 9 7 2}$ & 0,099 & $-0,119$ \\
$\mathrm{Mg}^{2+}\left(\mathrm{mg} \mathrm{L}^{-1}\right)$ & $\mathbf{0 , 9 7 0}$ & $-0,089$ & $-0,070$ \\
$\mathrm{SO}_{4}{ }^{2-}\left(\mathrm{mg} \mathrm{L}^{-1}\right)$ & $\mathbf{0 , 9 1 1}$ & 0,231 & 0,008 \\
$\mathrm{Cl}^{-}\left(\mathrm{mg} \mathrm{L}^{-1}\right)$ & $\mathbf{0 , 9 7 6}$ & 0,173 & $-0,098$ \\
$\mathrm{HCO}_{3}^{-}\left(\mathrm{mg} \mathrm{L}^{-1}\right)$ & 0,480 & $\mathbf{- 0 , 7 8 4}$ & 0,227 \\
$\mathrm{Variância} \mathrm{total}^{(\%)}$ & 70,5 & 13,4 & 8,4 \\
$\mathrm{Variância} \mathrm{cumulativa}(\%)^{70,5}$ & 83,9 & 92,3 \\
\hline
\end{tabular}

O plano formado pelas componentes principais, CP1 e CP2 (Figura 2), permitiu visualizar a separação das amostras dos reservatórios em quatro grupos: O Grupo I formado pelas amostras dos reservatórios Poxim (POX), Jacarecica I (JAC1), Jacarecica II (JAC2), Ribeira (RIB), Jabiberi (JAB) e Dionísio Machado (DIO); o Grupo II constituido pelos reservatórios Amargosa (AMR), Coité (COI), Cumbe (CUM), Macela (MAC), Ribeirópolis (RBR) e Taboca (TAB); o Grupo III composto pelos reservatórios Algodoeiro (ALG), Carira (CAR), Glória (GLO) e Três Barras (TBA) e o Grupo IV que contém apenas o reservatório Lagoa do Rancho (LRA). O Grupo I e II estão localizados na região negativa da CP1 e os Grupos III e IV na região positiva da CP1. Considerando que as concentrações iônicas crescem no sentido positivo da CP1 (Tabela 3), fica evidente que as amostras dos Grupos I e II se separam das amostras dos Grupos III e IV, por apresentarem menores concentracões iônicas $\left(\mathrm{Na}^{+}, \mathrm{K}^{+}, \mathrm{Ca}^{2+}, \mathrm{Mg}^{2+}, \mathrm{SO}_{4}{ }^{2-}, \mathrm{Cl}^{-}\right)$e portanto menores valores da $\mathrm{CE}$ e dos STD. A CP2 separou o Grupo I do Grupo II e o Grupo III do Grupo IV. Como as concentrações de $\mathrm{HCO}_{3}{ }^{-}$crescem no sentido negativo da CP2 (Tabela 3), conclui-se que as amostras do Grupo II e III são separadas respectivamente dos Grupos I e IV por exibirem concentrações mais elevadas do $\mathrm{HCO}_{3}^{-}$. 


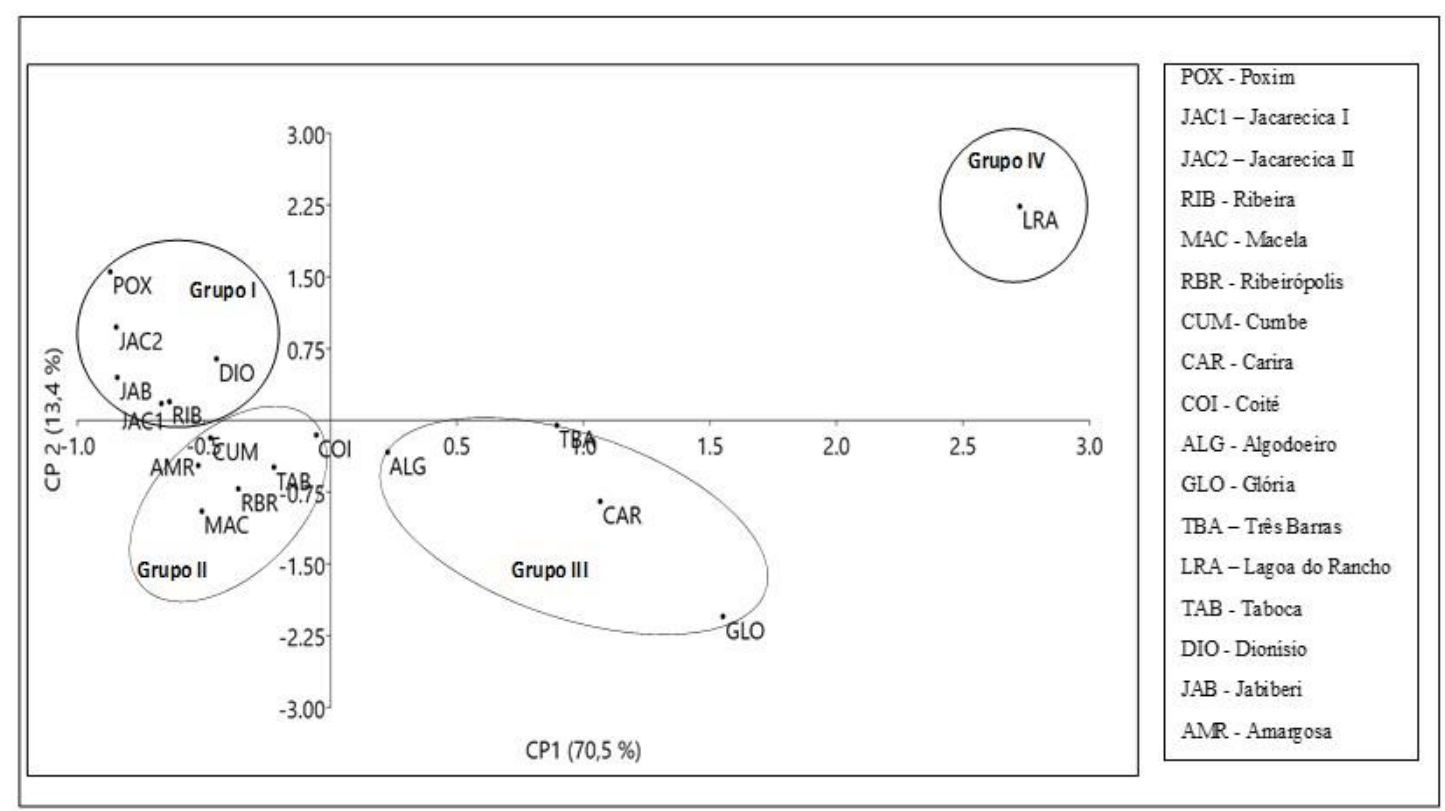

Figura 2: Localização das amostras dos reservatórios no plano formados pelas duas primeiras componentes principais CP1 $x$ CP2.

\section{Mecanismos que controlam a química da água}

O diagrama de Gibbs tem sido amplamente utilizado para elucidar os principais mecanismos naturais que controlam a composição química das águas superficiais [43, 44]. Considerando que os principais cátions que caracterizam as águas superficiais do mundo são o $\mathrm{Ca}^{2+}$ para corpos de água doce e $\mathrm{Na}^{+}$para corpos de água salinizados, Gibbs construiu um diagrama de dispersão plotando as razões $\mathrm{Na}^{+} /\left(\mathrm{Na}^{+}+\mathrm{Ca}^{2+}\right)$ em função dos STD. O diagrama tem a forma de um "bumerangue" e resume a evolução química das águas superficiais com base nos mecanismos de controle, que incluem a precipitação atmosférica, interação água - rocha (intemperismo) e evaporação. Águas com salinidade média $\left(70\right.$ a $\left.300 \mathrm{mg} \mathrm{L}^{-1}\right)$ e com razão $\mathrm{Na}^{+} /\left(\mathrm{Na}^{+}+\mathrm{Ca}^{2+}\right)<0,5$, se localizam à esquerda na parte do meio do "bumerangue", por apresentarem concentrações maiores de $\mathrm{Ca}^{2+} \mathrm{e}$ $\mathrm{HCO}_{3}{ }^{-}$comparadas às concentrações de $\mathrm{Na}^{+} \mathrm{e} \mathrm{Cl}^{-}$, indicando que o mecanismo final dominante é o intemperismo. Águas com elevada proporção de $\mathrm{Na}^{+} /\left(\mathrm{Na}^{+}+\mathrm{Ca}^{2+}\right)$ (aproximadamente 1,0) se distribuem nos extremos do "bumerangue" e podem ser resultantes da salinização pela evaporação (extremo superior direito) ou são de baixa salinidade, controladas pela quantidade de sais dissolvidos fornecidos pela precipitação atmosférica (extremo inferior direito) e que ainda não tiveram tempo suficiente de contato com os minerais para ocorrer modificações geoquímicas [44].

A água do reservatório Poxim está situada ainda no domínio da precipitação, mas com uma nítida evolução para o domínio do intemperismo (Figura 3). A água da chuva, ainda mais numa região costeira, tem uma forte contribuição do aerossol marinho e por isso, tem como íons dominantes o $\mathrm{Na}^{+} \mathrm{e} \mathrm{Cl}^{-}$. Na evolução para o domínio do intemperismo, a interação com as rochas passa a ser um processo mais importante e geralmente ocorre com relativa rapidez, passando o domínio iônico da água a ser $\mathrm{Ca}^{2+}{\mathrm{e} \mathrm{HCO}_{3}}^{-}$[44].

$\mathrm{Na}$ região do intemperismo, a água começa com o $\mathrm{HCO}_{3}{ }^{-}$como ânion dominante devido a ocorrência generalizada da calcita, mesmo em pequenas quantidades e pela sua solubilidade relativamente elevada. Com o aumento do tempo de residência, a água muda do tipo $\mathrm{HCO}_{3}{ }^{-}$para tipo $\mathrm{Cl}^{-}$e isso, geralmente é acompanhado da mudança do domínio do $\mathrm{Ca}^{2+}$ para $\mathrm{Na}^{+}$, associado ao aumento dos STD (aumento da salinidade) [44, 45].

Estão situados na região do intemperismo (Figura 3) os reservatórios Jacarecica I e II, Macela, Ribeira e Jabiberi com domínio iônico do $\mathrm{Na}^{+}$e $\mathrm{HCO}_{3}{ }^{-}$e os reservatórios Dionísio, Ribeirópolis, Amargosa e Cumbe com domínio iônico do $\mathrm{Na}^{+}$e $\mathrm{Cl}^{-}$. Nesses reservatórios portanto, as características químicas da água são controladas pela interação água - rocha. 
Morán-Ramírez et al. (2016) [6] estudando aquíferos dominados pelo intemperismo, na região de Guadalajara/México, observaram que a dominância catiônica foi $\mathrm{Na}^{+}>\mathrm{Ca}^{2+}>\mathrm{Mg}^{2+}>\mathrm{K}^{+}$, ao tempo que a dominância aniônica foi $\mathrm{HCO}_{3}{ }^{-}>\mathrm{Cl}^{-}>\mathrm{SO}_{4}{ }^{2-}$. Assim, atribuíram a origem do $\mathrm{HCO}_{3}{ }^{-}$ ao intemperismo dos carbonatos e rochas alumino-silicato e a do $\mathrm{Cl}^{-} \mathrm{e} \mathrm{Na}^{+}$ao aerossol marinho da precipitação atmosférica e a fontes litogênicas primárias como a halita ou evaporitos. Para Singh et al. (2011) [46] quando existe uma proporção elevado do $\mathrm{HCO}_{3}{ }^{-}$em relação aos outros ânions, indica o intemperismo principal de silicatos minerais.

Os reservatórios Taboca, Coité, Algodoeiro, Três Barras, Glória, Carira e Lagoa do Rancho estão localizados no domínio da evaporação (Figura 3). Com a evaporação é removida água pura e as concentrações iônicas vão aumentando com as sucessivas evaporações. No diagrama de Gibbs (Figura 3) observa-se que a salinização vai evoluindo no sentido do reservatório Taboca para o reservatório Três Barras, aumentando substancialmente as concentrações de $\mathrm{Na}^{+}$e $\mathrm{Cl}^{-}$na água. $\mathrm{O}$ dominio iônico vai progressivamente mudando de $\mathrm{Na}^{+}>>\mathrm{Ca}^{2+}>\mathrm{Mg}^{2+}$ e $\mathrm{Cl}^{-}>>\mathrm{HCO}_{3}^{-}>\mathrm{SO}_{4}{ }^{2-}$, em

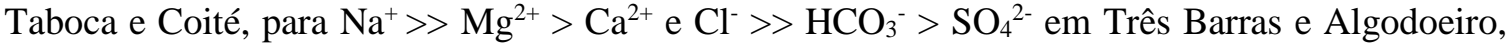
atingindo finalmente $\mathrm{Na}^{+}>>>\mathrm{Mg}^{2+}>\mathrm{Ca}^{2+} \mathrm{e}^{-}>>>\mathrm{SO}_{4}{ }^{2-}>\mathrm{HCO}_{3}{ }^{-}$em Glória, Carira e Lagoa do Rancho, reservatórios mais salinizados. Os elevados níveis de $\mathrm{Na}^{+} \mathrm{e} \mathrm{Cl}^{-}$são fortemente controlados pelo aumento das concentrações devido à evaporação [47].

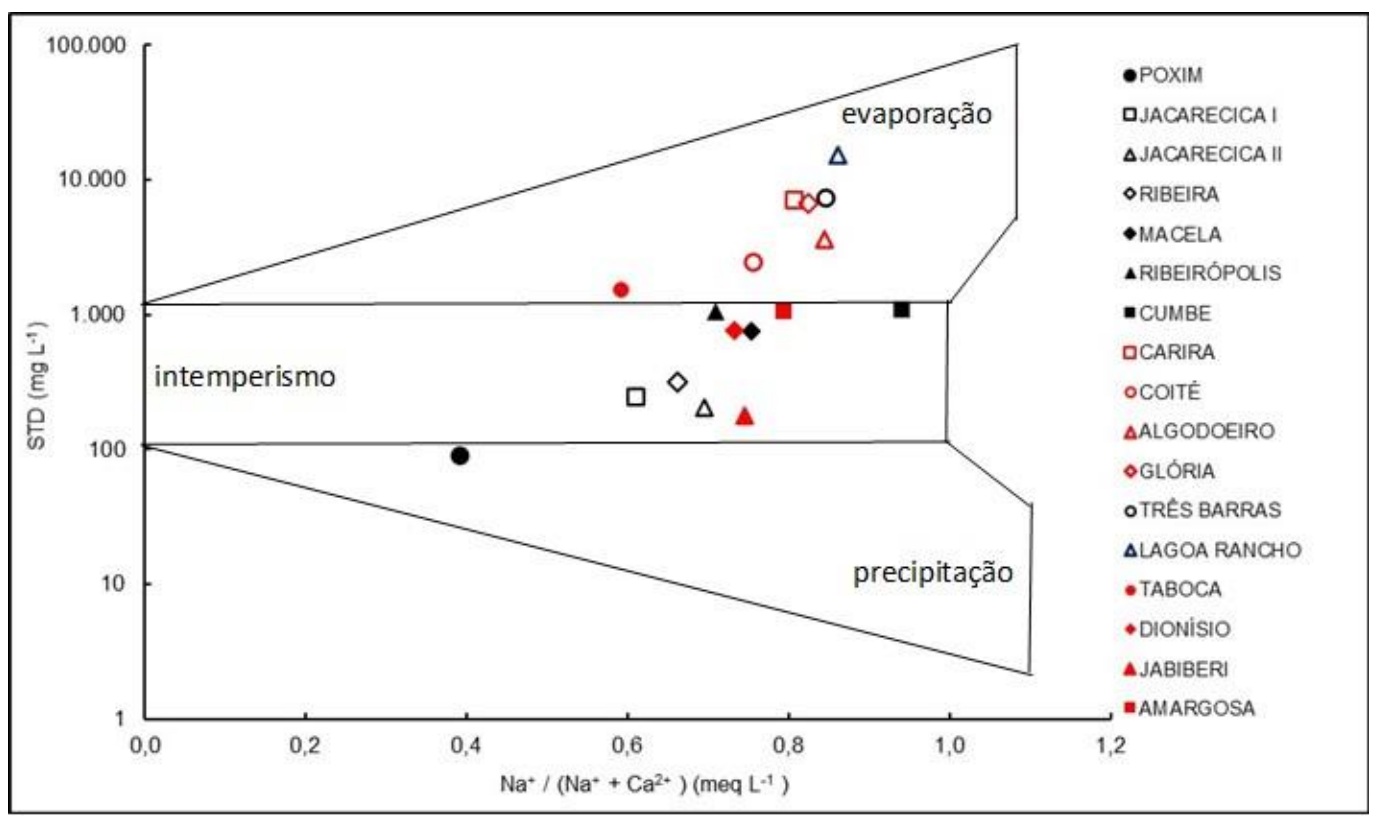

Figura 3: Distribuição das amostras dos reservatórios no diagarma de Gibbs.

O modelo de Hardie - Eugster tem sido utilizado para interpretar as variações químicas que ocorrem na água com a evaporação [1, 9, 48]. De acordo com o modelo modificado por Drever (1982) [1], as variações químicas são explicadas em termos de sucessivas divisões químicas. A divisão química ocorre quando o mineral menos solúvel começa a precipitar, removendo solutos e levando a mudança da composição da água. Isso resultará na variação das concentrações na água, dos íons componentes do precipitado, levando ao aumento da concentração do íon presente em maior concentração e decréscimo da concentração do íon presente em menor concentração. Em quase todas as águas naturais o primeiro mineral a precipitar é a calcita, sendo essa a primeira divisão química. Com isso, o $\mathrm{HCO}_{3}{ }^{-}$, progressivamente vai sendo removido da água levando ao aumento da concentração do $\mathrm{Cl}^{-}$, que passa a ser o ânion dominante. Após a precipitação da calcita, o próximo mineral a depositar é a gipsita, sendo essa a segunda divisão química. Com a precipitação da gipsita $\left(\mathrm{CaSO}_{4}\right)$ as mudanças iônicas na água podem seguir dois caminhos diferentes: (I) se na água após a precipitação da calcita permanecer o $\mathrm{Ca}^{2+}>\mathrm{SO}_{4}{ }^{2-}$, a concentração dos íons $\mathrm{SO}_{4}{ }^{2-}$ vai sendo reduzida com a evaporação, levando a água a uma composição iônica final tendo como constituintes iônicos principais $\mathrm{Na}^{+}, \mathrm{Ca}^{2+}, \mathrm{Mg}^{2+}$ e $\mathrm{Cl}^{-}$; (II) se ao contrário, na água após a 
precipitação da calcita, o $\mathrm{SO}_{4}{ }^{2-}>\mathrm{Ca}^{2+}$, a precipitação contínua da gipsita vai removendo o $\mathrm{Ca}^{2+}$ enquanto o $\mathrm{SO}_{4}{ }^{2-}$ vai crescer na solução, levando a água do reservatório a uma composição iônica final onde predominam os íons $\mathrm{Na}^{+}, \mathrm{Mg}^{2+}, \mathrm{SO}_{4}{ }^{2-}$ e $\mathrm{Cl}^{-}$.

Com base no modelo de Hardie - Eugster, modificado por Drever, é possível supor que para os reservatórios Taboca e Coité, as variações químicas durante as sucessivas evaporações seguiram o caminho (I), levando suas águas a composição iônica atual, que têm como íons principais $\mathrm{Na}^{+}, \mathrm{Ca}^{2+}$, $\mathrm{Mg}^{2+} \mathrm{e} \mathrm{Cl}^{-}$. Enquanto para os reservatórios Algodoeiro, Três Barras, Glória, Carira e Lagoa do Rancho a composição iônica atual, rica em $\mathrm{Na}^{+}, \mathrm{Mg}^{2+} \mathrm{e} \mathrm{Cl}^{-}$, foram atingidas seguindo o caminho (II). Observa-se ainda, que como previsto no caminho (II), as concentrações de $\mathrm{SO}_{4}{ }^{2-}$ cresceram e

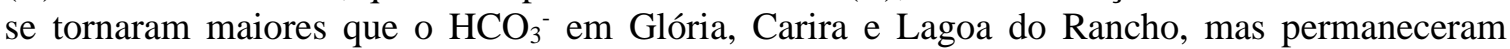
menores que o $\mathrm{HCO}_{3}{ }^{-}$em Algodoeiro e Três Barras. Ou seja, em relação ao $\mathrm{SO}_{4}{ }^{2-}$ a composição final da água desses reservatórios se desviou do modelo de Hardie - Eugster, que prever uma concentração do $\mathrm{SO}_{4}{ }^{2-}>\mathrm{Cl}$. De acordo com Wahed et al. (2015) [9] é possível que a precipitação da gipsita não afete muito a concentração do $\mathrm{SO}_{4}{ }^{2-}$, quando na água, antes da precipitação da gipsita, ocorra um excesso de $\mathrm{SO}_{4}{ }^{2-}$ em relação ao $\mathrm{Ca}^{2+}$, possivelmente é isso que pode ter contribuido para o desvio do modelo em relação ao $\mathrm{SO}_{4}{ }^{2-}$.

Além dos mecanismos naturais (precipitação, intemperismo, evaporação) existe também a possibilidade da composição química da água ser afetada por atividades antropogênicas. Para avaliar o impacto de atividades antropogênicas tem sido utilizada a relação entre $\mathrm{o}^{\mathrm{HCO}_{3}}{ }^{-}$e $\mathrm{o}$ somatório dos cátions maiores $\left(\sum\right.$ cátions $\left.=\left[\mathrm{Na}^{+}+\mathrm{K}^{+}+\mathrm{Ca}^{2+}+\mathrm{Mg}^{2+}\right)-\mathrm{Cl}^{-}\right][49,50]$ A relação linear (1:1) do $\mathrm{HCO}_{3}^{-}$com o $\sum$ cátions representa a distribuição dos íons originários somente do intemperismo dos carbonatos e silicatos [51]. Despejos urbanos, industriais e da atividade agrícola podem contribuir com a composição iônica e quando isso acontece, as amostras se desviam da linha $1: 1[50]$.

A Figura 4 mostra a dispersão das amostras dos reservatórios no gráfico do $\mathrm{HCO}_{3}{ }^{-}$com o $\sum$ cátions. As amostras dos reservatórios Dionísio, Ribeirópolis, Coité, Algodoeiro, Taboca, Carira, Glória e Lagoa do Rancho se desviaram da linha 1:1, confirmando que nesses reservatórios, além dos processos naturais, já ocorrem alterações na composição iônica de suas águas, como consequência de aportes antropogênicos. Esses impactos são mais expressivos nos reservatórios Glória, Carira e Lagoa do Rancho, pois apresentaram maiores desvios da linha 1:1.

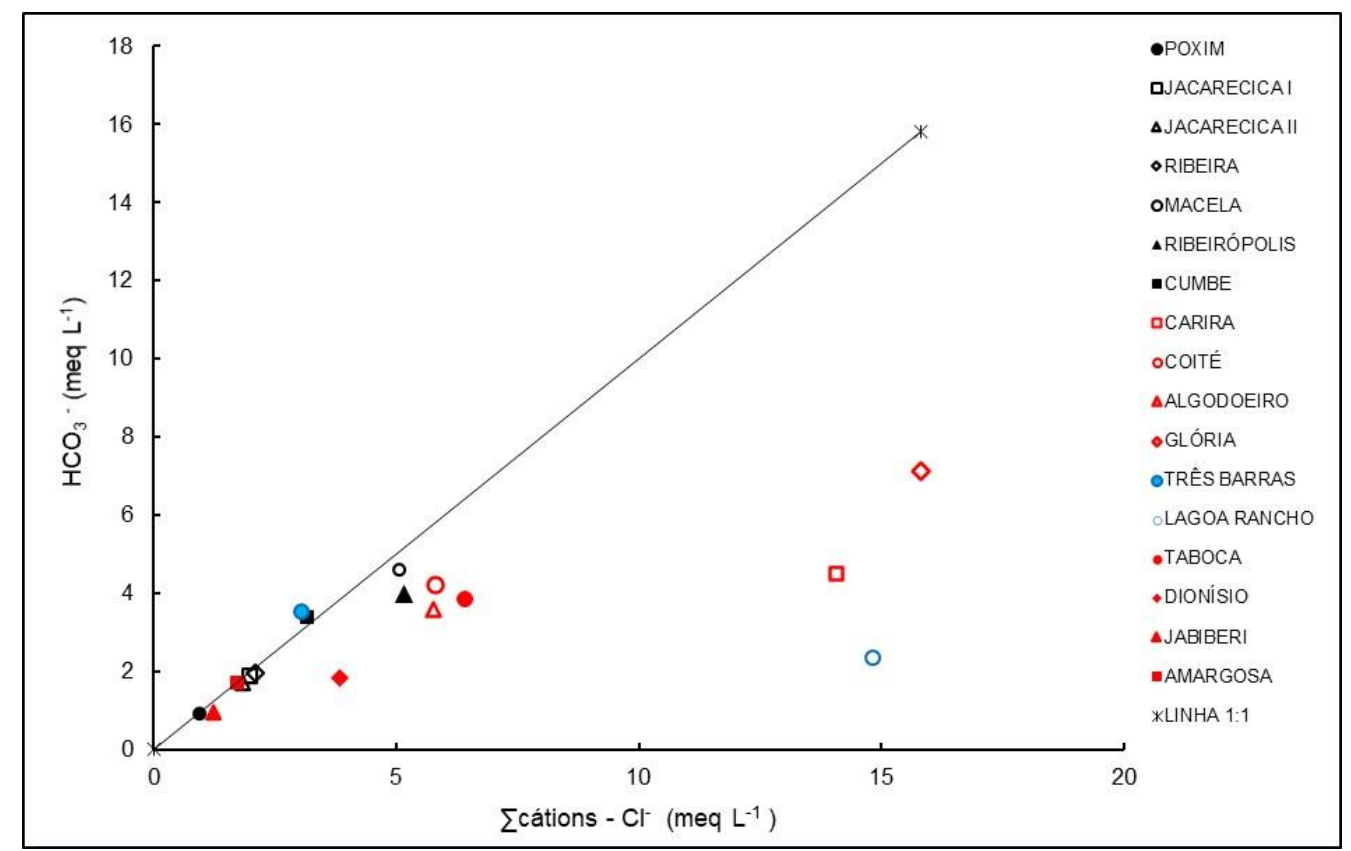

Figura 4: Gráficos de dispersão do $\mathrm{HCO}_{3}{ }^{-}$com o $\sum$ cátions para os valores médios das amostras dos reservatórios. 
Esse estudo mostra, portanto, que as características químicas das águas dos reservatórios de Sergipe, aqui estudados, são controladas principalmente, pela interação água - rocha (intemperismo) e pela elevada evaporação. Para a grande maioria dos reservatórios, a influência antropogênica parece ser bem menor quando comparada com os processos naturais, exceto para os reservatórios Glória, Carira e Lagoa do Rancho, onde o impacto antropogênico se mostrou expressivo.

A salinização de reservatórios é um problema recorrente no Nordeste brasileiro, principalmente na região semiárida onde a taxa de evaporação é em torno de $2000 \mathrm{~mm} / \mathrm{ano}$ [17, 19, 52-54]. De acordo com Santos et al. (2000) [19] a salinização tem aumentado com a idade dos reservatórios ou com o tempo de retenção hidráulica e por isso, uma estratégia possível para diminuir a velocidade do aumento da salinização, seria a renovação das águas acumuladas pelo controle das vazões defluentes. Para os reservatórios situados em regiões de agricultura irrigada é importante ter um manejo mais adequado da água de irrigação, pois o retorno da água de irrigação pode acelerar o processo de salinização, pelo aumento do intemperismo do material existente no entorno da área irrigada $[55,56]$

\section{CONCLUSÃO}

O diagrama de Gibbs foi usado para identificar os principais mecanismos naturais que controlam a composição química das águas dos principais reservatórios situados no estado de Sergipe, Nordeste do Brasil.

O reservatório Poxim está situado ainda na região do domínio da precipitação atmosférica, mas com uma nítida evolução para o domínio do intemperismo e por isso, a água tem como íons principais $\mathrm{Ca}^{2+}$ e $\mathrm{HCO}_{3}{ }^{-}$.

O intemperismo é o principal mecanismo que controla a química das águas dos reservatórios Jacarecica I, Jacarecica II, Macela, Ribeira e Jabiberi, com domínio iônico do $\mathrm{Na}^{+}$e $\mathrm{HCO}_{3}^{-}$, e dos reservatórios Dionísio, Ribeirópolis, Amargosa e Cumbe, com domínio iônico do $\mathrm{Na}^{+} \mathrm{e} \mathrm{Cl}^{-}$.

Os reservatórios Taboca, Coité, Algodoeiro, Três Barras, Glória, Carira e Lagoa do Rancho estão localizados no domínio da evaporação. Com o aumento da evaporação a salinização vai aumentando e a água progressivamente vai mudando de $\mathrm{Na}^{+}>>\mathrm{Ca}^{2+}>\mathrm{Mg}^{2+}$ e $\mathrm{Cl}^{-}>>\mathrm{HCO}_{3}{ }^{-}>$ $\mathrm{SO}_{4}{ }^{2-}$, em Taboca e Coité, para $\mathrm{Na}^{+}>>\mathrm{Mg}^{2+}>\mathrm{Ca}^{2+}$ e $\mathrm{Cl}^{-}>>\mathrm{HCO}_{3}{ }^{-}>\mathrm{SO}_{4}{ }^{2-}$ em Três Barras e Algodoeiro, atingindo finalmente $\mathrm{Na}^{+}>>>\mathrm{Mg}^{2+}>\mathrm{Ca}^{2+} \mathrm{e}^{-}>>>\mathrm{SO}_{4}{ }^{2-}>\mathrm{HCO}_{3}{ }^{-}$em Glória, Carira e Lagoa do Rancho, reservatórios mais salinizados.

Os resultados apontam, portanto, que as características químicas das águas dos reservatórios foram controladas principalmente por processos naturais, como a interação água - rocha e a evaporação, exceto para os reservatórios Glória, Carira e Lagoa do Rancho, onde o impacto antropogênico mostrou uma contribuição bastante expressiva.

\section{AGRADECIMENTOS}

Ao Conselho Nacional de Desenvolvimento Científico e Tecnológico (CNPq): Esse trabalho é parte do projeto "Hidrogeoquímica dos processos que controlam a salinização dos reservatórios de Sergipe", aprovado na Chamada Universal 2018, e conta com financiamento do CNPq.

A Coordenação de Aperfeiçoamento de Pessoal de Nível Superior (CAPES) pela bolsa PNPD concedida.

Esse trabalho utilizou os dados gerados no Projeto "Monitoramento de Mananciais Superficiais e Reservatórios do Estado de Sergipe". Por isso apresentamos nossos agradecimentos à Superintendência Especial de Recursos Hídricos e Meio Ambiente (SERHMA/SEDURBS) e ao Instituto Tecnológico e de Pesquisas de Sergipe (ITPS).

\section{REFERÊNCIAS BIBLIOGRÁFICAS}

1. Drever, JI. The geochemistry of natural waters: surface and groundwater environments. 3. ed. New Jersey (US): Prentice Hall;1982. 436 p. 
2. Huang X, Sillanpää, M Gjessing, ET VogT, DR. Water quality in the Tibetan Plateau: major ions and trace elements in the headwaters of four major Asian rivers. Sci Tot Environ. 2009 Dec;407(24):62426254, doi: 10.1016/j.scitotenv.2009.09.001

3. Chen Y, Cao P, Chen R, Teng Y. Effect of water-rock interaction on the morphology of a rock surface. Int J Rock Mech Min Sci. 2010 Jun;47(5):816-822, doi: 10.1016/j.ijrmms.2010.03.009

4. Yidana SM, Banoeng-Yakubo B, Asamoah-Sakyi P. Identifying key processes in the hydrochemistry of a basin through the combined use of factor and regression models. J Earth Syst Sci. 2012 May;121(2):491507, doi: 10.1007/s12040-012-0163-0

5. Zuddas P. Water-rock interaction processes seen through thermodynamics. Elements. 2010 Oct;6(5):305308, doi:10.2113/gselements.6.5.305

6. Moran-Ramírez J, Ledesma-Ruiz R, Mahlknecht J, Ramos-Leal, JA. Rockewater interactions and pollution processes in the volcanic aquifer system of Guadalajara, Mexico, using inverse geochemical modeling. Appl Geochem. 2016 May;68:79-94, doi: 10.1016/J.APGEOCHEM.2016.03.008

7. Kumarasamy P, Arthur JR, Dahms H, Byeon C, Ramesh R, Multivariate water quality assessment from the Tamiraparani river basin, Southern India. Environ. Earth Sci. 2014 Jul;71:2441-2451, doi: 10.1007/s12665-013-2644-0

8. Jiang L, Yao Z, Liu Z, Wang R, Wi S. Hydrochemistry and its controlling factors of rivers in the source region of the Yangtze River on the Tibetan Plateau. J Geochem Explo. 2015 Aug;155:76-83, doi:10.1016/j.gexplo.2015.04.009

9. Wahed AMSM, Mohamed EA, El-Sayed MI, M'nif A, Sillanpa, M. Hydrogeochemical Processes Controlling the Water Chemistry of a Closed Saline Lake Located in Sahara Desert: Lake Qarun, Egypt. Aquat Geochem. 2015 Feb;21:31-57, doi:10.1007/s10498-015-9253-3

10. Adams S, Titus, R, Pietersen, K, Tredoux, G, Harris, C. Hydrochemical characteristics of aquifers near Sutherland in the Western Karoo, South Africa. Hydrol. 2001 Jan;241(1-2):91-103, doi: 10.1016/S00221694(00)00370-X

11. Rademacher LK, Clark JF, Hudson GB, Erman DC, Erman N. Chemical evolution of shallow groundwater as recorded by springs, Sagehen basin; Nevada County, California. Chem Geol. 2001 Sept;179(1-4):37-51, doi: 10.1016/S0009-2541(01)00314-X

12. Guo HM, Wang YX. Hydrogeochemical processes in shallow quaternary aquifers from the northern part of the Datong Basin, China. Appl Geochem. 2004 Jan;19(1):19-27, doi: 10.1016/S0883-2927(03)001288

13. Subramani T, Rajmohan N, Elango L. Groundwater geochemistry and identification of hydrogeochemical processes in a hard rock region, Southern India. Environ. Monit Assess. 2010 Feb;162;123-137, doi:10.1007/s10661-009-0781-4

14. Lin CY, Abdullah MH, Praveena SM, Yahaya AHB, Musta B. Delineation of temporal variability and governing factors influencing the spatial variability of shallow groundwater chemistry in a tropical sedimentary island. J Hydrol. 2012 Mar;432(433):26-42, doi: 10.1016/j.jhydrol.2012.02.015

15. Lerman A. Saline lakes' response to global change. Aquat Geochem. 2009 Dec;15:1-5, doi: 10.1007/s10498-008-9058-8

16. Carpenter SR, Stanley EH, Zanden MJV. State of the World's Freshwater Ecosystems: Physical, Chemical, and Biological Changes. Annu Rev Environ Resour. 2011 Jul;36:75-99, doi: 10.1146/annurevenviron-021810-094524

17. Palácio HAQ, Araújo Neto J R, Meireles ACM, Chaves LCG. Similaridade e fatores determinantes na salinidade das águas superficiais do Ceará, por técnicas multivariadas. Rev Bras Eng Agric Amb. 2011 Aug;15(4):395-402, doi: 10.1590/S1415-43662011000400011.

18. Silva PCG, Moura MSB, Kiill LHP, Brito LTL, Pereira LA, Sa IB, Correia RC, Teixeira AHC, Cunha TJF, Guimarães FC. Caracterização do Semiárido brasileiro: fatores naturais e humanos. In: Sa IB, Silva PCG, editores. Semiárido brasileiro: pesquisa, desenvolvimento e inovação. Petrolina (PE): Embrapa Semiárido; 2010. p. 18-48.

19. Santos JS, De Oliveira E, Massaro S. Avaliação da salinização de açudes no semiárido brasileiro por ICPAES. Quím Nova. 2000 Aug;23(4):453-456, doi: 10.1590/S0100-40422000000400004

20. Silva EL. Processos geoquímicos que controlam a salinização dos reservatórios Carira e Coité, bacia hidrográfica do rio Vaza-Barris, estado de Sergipe [dissertação]. São Cristóvão (SE): Universidade Federal de Sergipe, Programa de Pós Graduação em Recursos Hídricos; 2020. 98 p.

21. Dória JR. Processos hidrogeoquímicos que controlam a química da água dos reservatórios Cumbe e Ribeirópolis no estado de Sergipe [dissertação]. São Cristóvão (SE): Universidade Federal de Sergipe, Programa de Pós Graduação em Recursos Hídricos; 2020. 56 p.

22. Garcia HL, Silva VL, Marques LP, Garcia CAB, Alves JPH, Silva MG, Carvalho FO. Nível trófico do reservatório de Jacarecica I - Sergipe - Brasil. Sci Plena. 2012 Jul;8(7):[about 9 p.]. 
23. Santos CEO, Peixoto JS, Alves JPH. Geoquímica das águas do reservatório Poção da Ribeira, Agreste Central de Sergipe. Sci Plena. 2017 Oct;13(10):1-10, doi: 10.14808/sci.plena.2017.109906

24. Lima RS. Qualidade da água dos reservatórios situados na bacia hidrográfica dos rios Piauí - Real: uma avaliação com base em técnicas estatísticas multivariadas e razões iônicas [dissertação]. São Cristóvão (SE): Universidade Federal de Sergipe, Programa de Pós Graduação em Recursos Hídricos; 2015. 101 p.

25. Neves MA. Caracterização e variação espaço - temporal da qualidade da água do reservatório do rio Poxim, São Cristóvão - Sergipe [dissertação]. São Cristóvão (SE): Universidade Federal de Sergipe, Programa de Pós Graduação em Recursos Hídricos; 2016. 95 p.

26. Companhia de Desenvolvimento de Recursos Hídricos e Irrigação de Sergipe (Cohidro). Irrigação. Perímetros [Internet]; 2020 [acessado em 10 jan 2020]. Disponível em: https://cohidro.se.gov.br

27. Sena IMN, Monteiro ASC, Alves JPH. Variações na qualidade da água e no estado trófico do Reservatório Macela no período de 2004 a 2014. In: de Souza IF, Monteiro ASC, Santana NRF, organizadores. Olhar dos recursos e do meio ambiente do estado de Sergipe. Belo Horizonte (MG): Poisson; 2020. p. 34-47, doi: 10.36229/978-85-7042-208-8.CAP.03.

28. Santos RA, Martins AAM, Neves JP, Leal RA. Programa Levantamentos Geológicos Básicos do Brasil - PLGB. Geologia e recursos minerais do Estado de Sergipe. Escala 1:250.000. Texto explicativo do Mapa geológico do Estado de Sergipe. Brasília (DF): CPRM/DIEDIG/DEPAT, CODISE; 2001. 156 p. Disponível em: http://rigeo.cprm.gov.br/jspui/bitstream/doc/19439/1/proj_sergipe_relatorio.pdf

29. Alencar NRO. Processos hidrogeoquímicos envolvidos na salinização dos reservatórios Algodoeiro e Três Barras situados na região do baixo São Francisco no estado de Sergipe [dissertação]. São Cristóvão (SE): Universidade Federal de Sergipe; Programa de Pós Graduação em Recursos Hídricos; 2020. 120 p.

30. SAR Sistema de Acompanhamento de Reservatórios. Brasília (DF): Agência Nacional de Águas (ANA); 2020 [acesso em 22 jan 2020]. Disponível em: https://www.ana.gov.br/sar/nordeste-e-semiarido/sergipe

31. Melo APS. Avaliação da qualidade da água dos reservatórios Algodoeiro e Glória, através do índice de qualidade de água de reservatório - IQAR [dissertação]. São Cristóvão (SE): Universidade Federal de Sergipe. Programa de Pós Graduação em Recursos Hídricos; 2016. 95 p

32. Santos CEO. Qualidade da água do reservatório Poção da Ribeira: uma avaliação com base em técnicas Estatísticas multivariadas e nos processos geoquímicos de salinização [dissertação]. São Cristóvão (SE): Universidade Federal de Sergipe. Programa de Pós Graduação em Recursos Hídricos; 2016.97 p

33. Lima RS, Alves JPH. Avaliação da qualidade da água dos reservatórios localizados nas bacias hidrográficas dos rios Piauí - Real, utilizando o índice de qualidade da água (IQA). Sci Plena. 2017 Oct;13(10):1-10, doi: 10.14808/sci.plena.2017.109918

34. Alves JPH, Fonseca LC, Chielle RSA, Macedo LCB. Monitoring water quality of the Sergipe River basin: an evaluation using multivariate data analysis. Rev Bras Recur Hídricos. 2018 Jul;23(e27):1-12, doi: $10.1590 / 2318-0331.231820170124$

35. Apha. Standard methods for the examination of water and wastewater. 22nd ed. Washington (US): American Public Health Association; 2012.

36. Yaouti FE, Mandour AE, Khattach D, Benavente J. Kaufmann, O. Salinization processes in the unconfined aquifer of Bou-Areg (NE Morocco): A geostatistical, geochemical, and tomographic study. Appl Geochem. 2009 Jan;24(1):6-31, doi: 10.1016/J.APGEOCHEM.2008.10.005

37. Singh KP, Malik A, Mohan D, Sinha S. Multivariate statistical techniques for the evaluation of spatial and temporal variations in water quality of Gomti River (India): a case study. Water Res. 2004 Nov;38(18):3980-3992, doi: 10.1016/j.watres.2004.06.011

38. Shrestha S, Kazama F. Assessment of surface water quality using multivariate statistical techniques: a case study of the Fuji river basin, Japan. Environm Modell Software. 2007 Apr;22(4):464-47, doi: 10.1016/j.envsoft.2006.02.001

39. Zhu B, Wang X, Rioual P. Multivariate indications between environment and ground water recharge in a sedimentary drainage basin in northwestern China. J Hydrol. 2017 Jun;549:92-113, doi: 10.1016/j.jhydrol.2017.03.058

40. Khalil B, Ouarda TBMJ. Statistical approaches used to assess and redesign surface water-quality monitoring networks. J Environm Monit. 2009 Oct;11:1915-1929, doi: outubro, 10.1039/b909521g

41. Hammer O, Harper DAT, Ryan PD. Paleontological statistic. Oslo (Norway): University of Oslo; 2001 [acessado em 10 jan 2018]. Disponível em: http://folk.uio.no/ohammer/past

42. Delgado C, Pacheco J, Cabrera, A, Batlori E; Orellana, R, Bautista F. Quality of groundwater for irrigation in tropical karst environment: The case of Yucatán, Mexico. Agric Water Manage. 2010 Oct;97(10):1423-1433, doi:10.1016/j.agwat.2010.04.006

43. Gibbs RJ. Mechanisms Controlling World Water Chemistry. Science. 1970 Dec;170(3962):1088-1090, doi: $10.1126 /$ science. 170.3962 .1088

44. Marandia A, Shand P. Groundwater chemistry and the Gibbs Diagram. Appl Geochem. 2018 Oct;97:209212, doi: 10.1016/j.apgeochem.2018.07.009 
45. Chebotarev, II. Metamorphism of natural waters in the crust of weathering. Geochem. Cosmochim. Acta. 1955 Aug;8(1-2):137-170, doi: 10.1016/0016-7037(55)90015-6.

46. Singh K, Hundal, HS, Singh, D. Geochemistry and assessment of hydrogeochemical processes in groundwater in the southern part of Bathinda district of Punjab, northwest India. Environ Earth Sci. 2011 Mar;64(7):1823-1833, doi: 10.1007/s12665-011-0989-9

47. Huang X, Sillanpää, M, Gjessing, ET, Vogt, DR. Water quality in the Tibetan Plateau: major ions and trace elements in the headwaters of four major Asian rivers. Sci Tot Environ. 2009 Dec;407(24):62426254, doi: 10.1016/j.scitotenv.2009.09.001

48. Wahed AMSM, Mohamed EA, El-Sayed MI, M'nif A, Sillanpa M. Geochemical modeling of evaporation process in Lake Qarun, Egypt. J Afr Earth Sci. 2014 Sept;97:322-330, doi: 10.1016/j.jafrearsci.2014.05.008

49. Reddy AGS, Saibaba B, Sudarshan, G. Hydrogeochemical characterization of contaminated groundwater in Patancheru industrial area, southern India. Environ Monit Assess. 2012 Jul;184:3557-3576, doi:10.1007/s10661-011-2208-2

50. Barzegar R, Moghaddam AA, NazemI AH, Adamowski, J. Evidence for the occurrence of hydrogeochemical processes in the groundwater of Khoy plain, northwestern Iran, using ionic ratios and geochemical modeling. Environ Earth Sci. 2018 Aug;77(16):1-17 doi: 10.1007/s12665-018-7782-y

51. Kim K. Long-term disturbance of groundwater chemistry following well installation. Groundwater. 2003 Dec;41:780-789, doi: 10.1111/j.1745-6584.2003.tb02419.x

52. Souza FDAD, Campos JNB. Um método paramétrico de avaliação do potencial de salinização de reservatórios aplicado a regiões semiáridas. Rev Bras Recur Hídricos. 2005 Jun;10(2):5-14, doi: 10.21168/RBRH.V10N2.P5-14

53. Meireles ACM, Frischkorn H; Andrade EM. Sazonalidade da qualidade das águas do açude Edson Queiroz, bacia do Acaraú, no Semiárido cearense. Rev Ci Agron. 2007 Sept;38(1):25-31.

54. Fontes AS, Zucchi MR, Medeiros YDP, Azevedo AEG. Avaliação dos fatores intervenientes no processo de salinização em reservatórios superficiais do semiárido brasileiro. Rev Bras Rec Hídricos. 2015 Sept;20(3):708-721, doi: 10.21168/rbrh.v20n3.p708-721

55. Koh DC, Ko KS, Kim, Lee SG, Chang HW. Effect of agricultural land use on the chemistry of groundwater from basaltic aquifers, Jeju Island, South Korea. Hydrogeol J. 2007 Jun;15:727-743, doi: 10.1007/s10040-006-0142-0

56. Johansson O, Aimbetov I, Jarsjö J. Variation of groundwater salinity in the partially irrigated Amudarya River delta, Uzbekistan. J Mar Syst. 2009 Mar;76(3):287-295, doi: 10.1016/j.jmarsys.2008.03.017 